\title{
Myocardial ischaemic/ reperfusion injury in the anaesthetized rabbit: comparative effects of halothane and isoflurane
}

The effects of halothane and isofturane anaesthesia on myocardial injury in rabbits subjected to coronary artery ligation and subsequent reperfusion were analyzed. Although halothane and isoflurane (at inspired concentrations of 1.0 and 1.5 per cent, respectively) exerted comparable effects on cardiovascular status during ischaemic and reperfusion phases, greater preservation of subcellular integrity (as assessed by mitochondrial and sarcoplasmic reticular ATPase activities and myocardial ionic alterations) and a lower incidence of ventricular fibrillation and severe hypotension occurred with halothane. Our results indicate that in studies of experimental myocardial ischaemia anaesthetics may, independently of cardiovascular actions, influence the nature and extent of resulting injury, possibly by virtue of their differing effects on subcellular membrane systems.

\section{Key words}

MYOCARDIUM: ischaemic/reperfusion injury; ANAESTHETICS, vOLATILE: halothane, isoflurane; BlOCHEMISTRY: subcellular enzyme alterations, ionic compositional changes.

From Department of Pharmacology and Therapeutics, Faculty of Medicine, The University of British Columbia, 2176 Health Sciences Mall, Vancouver, B.C., Canada V6T 1W5, where correspondence should be addressed to Dr. Godin.

This work was supported by a grant from the British Columbia Heart Foundation.
Acute myocardial ischaemia initiates a complex series of initially reversible and, subsequently, irreversible processes of cellular injury ' which may continue for some time after the acute episode. It is clear from the extensive literature on experimental myocardial infarction that cellular membrane alternations are a characteristic feature of tissue damage $^{2-3}$ and that substances with membraneactive properties are able to limit the extent of necrosis. $^{4-6}$

A major uncertainty in most animal models of acute myocardial infarction relates to the use of anaesthetics (frequently pentobarbitone) whose influence on ischaemia-induced membrane alterations has not been systematically investigated. The direct interaction of general anaesthetics with membrane components ${ }^{7-9}$ and their effects on cellular metabolism, myocardial function, and peripheral and coronary vasculature may all modify the extent of myocardial ischaemic injury.

The use of barbiturate anaesthesia in studies of experimental myocardial ischaemia introduces interpretational complexities not only because of the ability of the barbiturates to modify the electrical properties of the myocardium following coronary artery ligation. ${ }^{10}$ They have been shown to have protective effects against ischaemia-related damage in several tissues ${ }^{11,12}$ including the myocardium, ${ }^{13,14}$ but, on the other hand, a recent study by Au et al. ${ }^{15}$ has shown that in rats subjected to coronary artery ligation under halothane, meperidine or pentobarbitone anaesthesia, the incidence of arrhythmias and 
mortality was greatest in the pentobarbitone-treated animals.

It seems likely, then, that anaesthetics are able to influence, to differing degrees, the course of myocardial ischaemic injury, probably as the result of a complex interplay between effects on the cardiovascular system and subcellular alterations at the membrane level. In the present study, we have examined the effects of halothane and isoflurane, two clinically useful inhalational agents with different cardiovascular actions, on the characteristics of myocardial ischaemic/reperfusion injury in rabbits subjected to a 40 -min period of ischaemia induced by coronary artery ligation followed by $60 \mathrm{~min}$ of reperfusion. A multi-level approach has been utilized wherein the effects of ischaemia and reperfusion were analyzed in terms of alterations in myocardial functon and in biochemical and chemical properties. The results obtained were compared with those we have previously found using pentobarbitone anaesthesia in the same experimental model system. ${ }^{6}$

\section{Methods}

Unpremedicated male New Zealand white rabbits weighing between $2-3 \mathrm{~kg}$ were anaesthetized with either halothane or isoflurane in oxygen, orally intubated and mechanically ventilated. A Dräger Halothan vaporizer was used to administer both anaesthetic agents. This was felt to be acceptable because of their similarities in vapour pressures, but, to minimize cross-contamination, halothanetreated animals preceded and followed isofluranetreated animals; for each drug, however, the experimental groups (control, ischaemic and ischaemic/ reperfused) were randomized.

Following intubation, needle electrodes were placed for continuous monitoring of the electrocardiogram. An intravenous route for administration of saline was established in a marginal ear vein and the left carotid artery was exposed and cannulated for measurement of arterial pressure using a Statham P23ID transducer connected to a Grass polygraph (model 7 PCPB). A median sternotomy was then performed and a ligature/occluder placed loosely around the major marginal branch of the circumflex coronary artery. A Jelco 20 -gauge catheter connected to a Statham pressure transducer was inserted into the left ventricle via the apex and the left ventricular signal together with its differentiated form was recorded using a Grass model 7 P2OC differentiator. When these surgical manipulations had been completed, the inspired concentrations of halothane or isoflurane were reduced to 1.0 and 1.5 per cent, respectively (by dial setting) - concentrations found to just prevent spontaneous movement in all animals. These inspired concentrations were utilized for the remainder of the experiment. The animals rested for at least $15 \mathrm{~min}$ before any subsequent procedures were undertaken.

Twenty-six rabbits then underwent $40 \mathrm{~min}$ of myocardial ischaemia (induced by tightening the coronary artery occluder) under halothane anaesthesia and half of these underwent subsequent reperfusion (by loosening the ligature) for $60 \mathrm{~min}$. Previous work utilizing microspheres to measure blood flow showed that tightening of the coronary artery occluder in this fashion reduced coronary blood flow to less than five per cent of baseline, while release of the occluder restored flow. Twenty animals were treated similarly under isoflurane anaesthesia of which ten underwent subsequent reperfusion. Sham-operated controls $(n=8)$ were included in each anaesthetic group. Ventricular fibrillation was treated with internal electrical cardioversion and cardiac massage was employed if the systolic blood pressure dropped to below $25 \mathrm{mmHg}$.

At the conclusion of the experiment (i.e., after $40 \mathrm{~min}$ of ischaemia or $40 \mathrm{~min}$ of ischaemia with 60 min of reperfusion), the heart was excised and dropped into ice-cold isotonic sucrose. The ligature was tightened for the sham-operated and reperfused samples and the occluded zone identified by lack of blanching following perfusion of the heart with cold isotonic sucrose via the aortic root. Subendocardial tissue samples were taken for ion and ATP analyses, and the remainder of the myocardial tissue was homogenized and fractionated for ATPase marker enzyme analysis. All of these chemical and biochemical characterization procedures have been described in a previous publication. ${ }^{6}$

\section{Statistical analysis}

The experimental data were subjected to an analysis of variance and specific group differences were determined using a standardized Tukey's test at a significance level of $p<0.05$. Chi-squared analysis was applied to the haemodynamic and electrocardiographic data, also at a significance level of $p<$ 


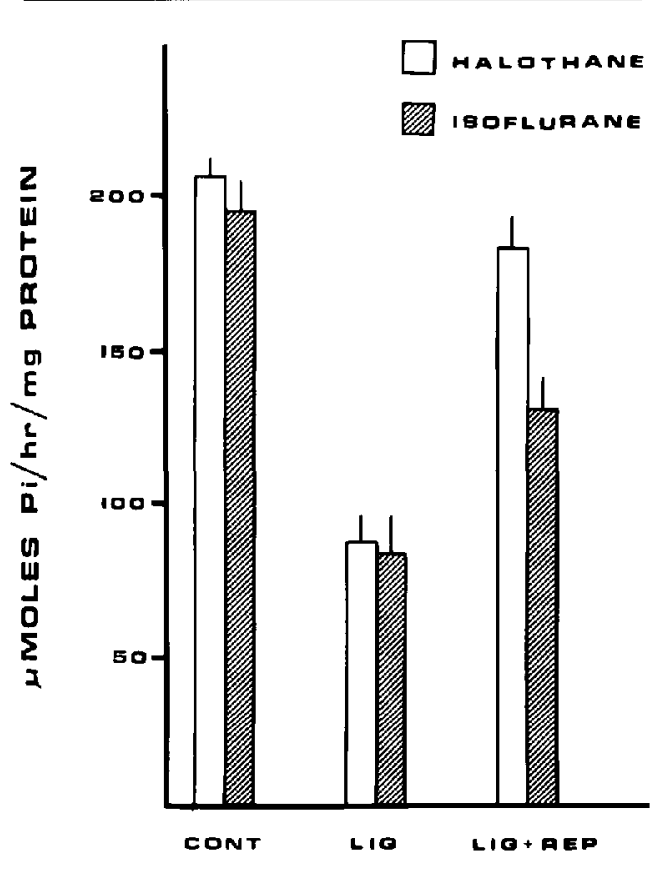

FIGURE 1 Mitochondrial ATPase activities in halothane- and isoflurane-anaesthetized control (cont) rabbits, in animals subjected to $40 \mathrm{~min}$ of coronary artery ligation without (lig) or with (lig + rep) subsequent reperfusion for $60 \mathrm{~min}$. (All values are given as mean \pm SEM. Numbers of animals in cont, lig and lig + rep groups were 8,9 and 10 , respectively, for hulothane and 8,10 and 10 for isoflurane.)

0.05 . All values are expressed as mean \pm standard error. Discrepancies between total numbers of animals used and the numbers reported for biochemical and chemical analyses are due to loss of tissue specimens or errors in the analytical procedures.

\section{Results}

The isolated occluded zones, comprising 30-40 per cent of the left ventricular weight, were not significantly different in the two anaesthetic groups and were comparable in magnitude to those observed previously using pentobarbitone as the anaesthetizing agent. ${ }^{6}$ Oesophageal temperature dropped by approximately $3^{\circ} \mathrm{C}$ from baseline by the end of the ligation period, and approximately another $1^{\circ} \mathrm{C}$ by the end of reperfusion. Again, there were no significant differences between the two

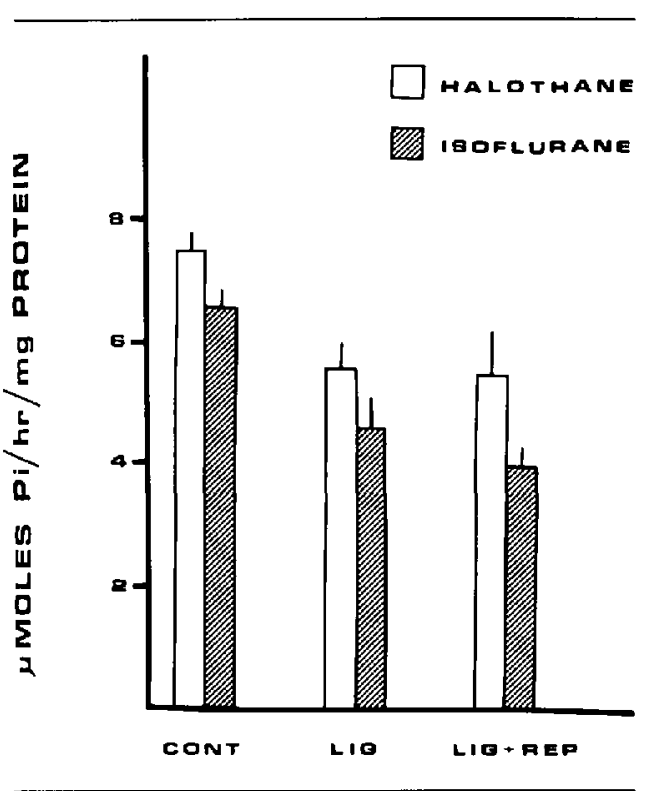

FGGURE 2 Sarcolemmal ATPase activities in halothane- and isoflurane-anaesthetized control, coronary ligated and coronary ligated/reperfused rabbits. (Experimental conditions and abbreviations as in Figure 1.)

inhalational anaesthetics. Estimated blood losses and fluid replacements did not differ significantly for both anaesthetic groups.

\section{Biochemical measurements}

Alterations in the integrity of subcellular organelles following ischaemia and reperfusion were analyzed in terms of changes in the activity of specific marker enzymes. Mitochondrial ATPase activity was reduced to approximately 40 per cent of control with both anaesthetics following $40 \mathrm{~min}$ of ischaemia. With subsequent reperfusion ( $60 \mathrm{~min}$ ) ATPase activity was restored to a value not significantly different from control in the case of halothane but remained significantly depressed $(p<0.05)$ in the isoflurane-treated animals (Figure 1). The sarcolemmal $\mathrm{Na}^{+}, \mathrm{K}^{+}$-stimulated ATPase exhibited a decrease of approximately 25 per cent relative to control with both anaesthetics during the ischaemic phase and no reversal of this inhibition was apparent with either anaesthetic during reperfusion, reperfusion values being significantly $(p<0.05)$ lower than controls (Figure 2). The $\mathrm{Ca}^{2+}, \mathrm{K}^{+}$-dependent ATPase activity of the sarcoplasmic reticulum had 


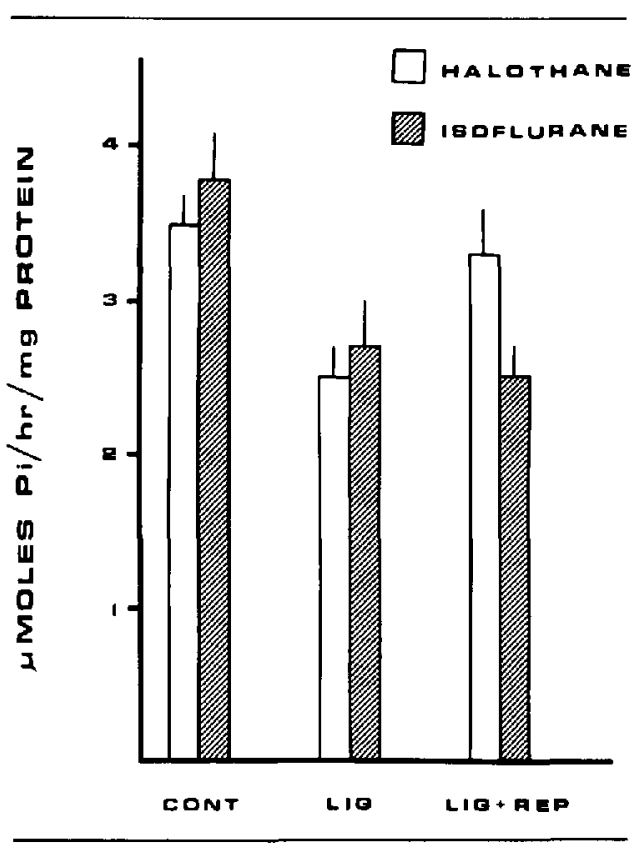

FIGURE 3 Sarcoplasmic reticulum ATPase activities in halothane- and isoflurane-anaesthetized control, coronary ligated and coronary ligated/reperfused rabbits. (Experimental conditions and abbreviations as in Figure 1, except that $n=7$ in the control isoflurane group.)

fallen to approximately 70 per cent of control independently of the anaesthetic employed by the end of the ischaemic period but upon reperfusion recovery was apparent in the halothane-anaesthetized animals (activity did not differ significantly from control), whereas the activity of this enzyme showed a further small decrease in the isoflurane group (Figure 3 ).

\section{Chemical analyses}

Tissue ATP content decreased to approximately 30 per cent of control during ischaemia and no restoration was observed with either anaesthetic on reperfusion (Figure 4). Although the levels of major cations in whole myocardial tisue did not change during the ischaemic period, in both experimental groups reperfusion was associated with significant $(p<0.05$ ) increases in tissue $\mathrm{Na}$ (greater for isoflurane than halothane) and Ca levels; in isofluraneanaesthetized animals significant decreases $(\mathrm{p}<$ 0.05 ) in $\mathrm{K}$ and $\mathrm{Mg}$ were also present after reperfusion (Table I).

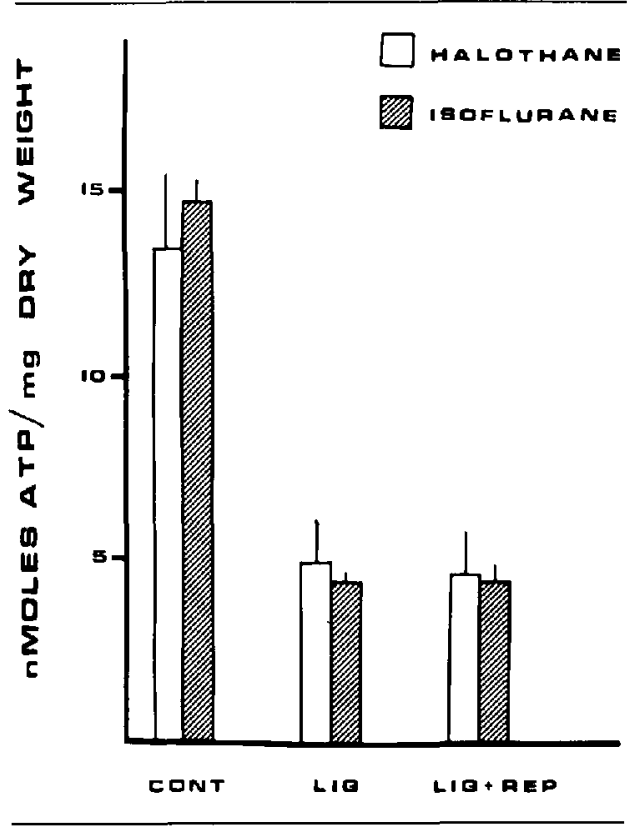

FIGURE 4 Myocardial ATP levels in halothane- and isoflurane-anaesthetized control, coronary ligated and coronary ligated/reperfused rabbits. (Experimental conditions and abbreviations as in Figure 1, except that numbers of animals in cont, lig and lig + rep groups were 8, 11 and 11 , respectively, for halothane and 6,9 and 10 for isoflurane.)

\section{Cardiovascular changes}

Preligation systolic blood pressure was significantly higher $(\mathrm{p}<0.05)$ in isoflurane-anaesthetized animals, although diastolic blood pressures did not differ significantly between the two groups. Ligation produced approximately 35 per cent reduction in systolic and diastolic pressures with isoflurane as compared with a 25 per cent reduction with halothane (Figure 5). Pressures after ligation in the two groups did not differ significantly and there was no change with either anaesthetic during reperfusion (Figure 5). As with systolic pressure, left ventricular contractility (assessed indirectly by $\mathrm{dP} / \mathrm{dt}_{\max }$ ) prior to ligation was also higher $(\mathrm{p}<0.05)$ in the isoflurane-anaesthetized animals and there was a greater decline in $\mathrm{dP} / \mathrm{dt}_{\max }$ upon ligation with isoflurane (47 per cent) as compared with halothane (32 per cent), both being statistically significant $(p<0.05)$. However, contractilities after ligation or reperfusion were not significantly different (Figure 6). Variations in heart rate under control or 


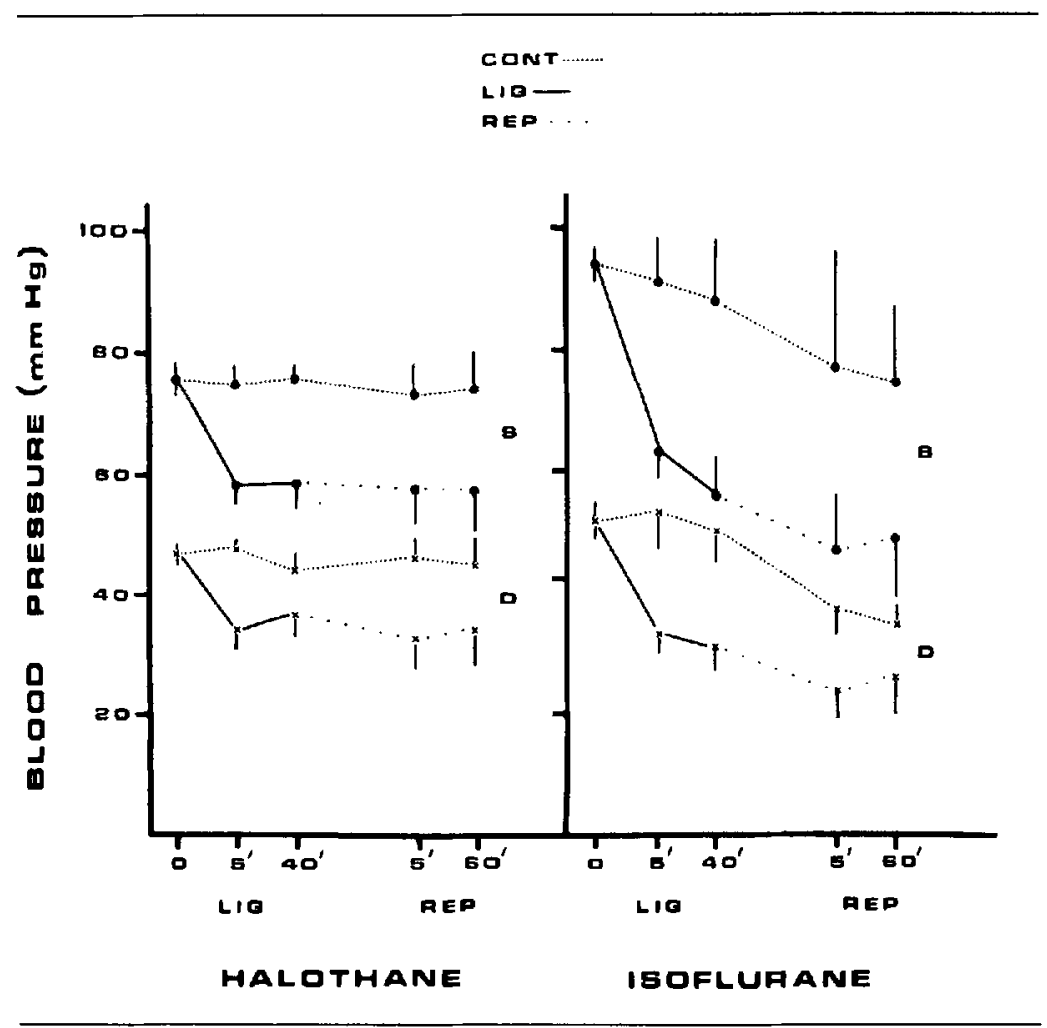

FIGURE 5 Systolic (S) and diastolic (D) blood pressure changes during ligation (lig) and reperfusion (rep) phases in halothane- and isoflurane-anaesthetized rabbits. (Experimental conditions as described in Figure 1.)

TABLE I Cation contents (ng atoms/mg dry weight) of intact myocardial tissue samples from control (CON), ischaemic (ISCH) and ischaemic/reperfused, (REP) hearts of rabbits anaesthetized with halothane or isoflurane

\begin{tabular}{lrlllr}
\hline Drug & $n$ & $\mathrm{Na}$ & $K$ & $\mathrm{Mg}$ & $\mathrm{Ca}$ \\
\hline Halothane & & & & & \\
CON & 8 & $180 \pm 11$ & $336 \pm 8$ & $30 \pm 0.5$ & $7.4 \pm 0.8$ \\
ISCH & 13 & $209 \pm 11$ & $347 \pm 13$ & $29 \pm 0.8$ & $5.6 \pm 0.5$ \\
REP & 11 & $347 \pm 38^{*}$ & $291 \pm 24$ & $26 \pm 2.5$ & $22.3 \pm 5.6^{*}$ \\
& & & & & \\
Isoflurane & & & & & \\
CON & 8 & $185 \pm 10$ & $381 \pm 13$ & $30 \pm 0.7$ & $5.8 \pm 0.4$ \\
ISCH & 8 & $230 \pm 31$ & $322 \pm 24$ & $28 \pm 1.4$ & $6.6 \pm 1.0$ \\
REP & 10 & $466 \pm 31^{* \dagger}$ & $273 \pm 15^{*}$ & $22 \pm 1.0^{*}$ & $23.9 \pm 4.0^{*}$ \\
\hline
\end{tabular}

All values are given as mean \pm SEM.

${ }^{*} \mathrm{P}<0.05$, relative to control.

$\dagger P<0.05$, between halothane and isoflurane. 


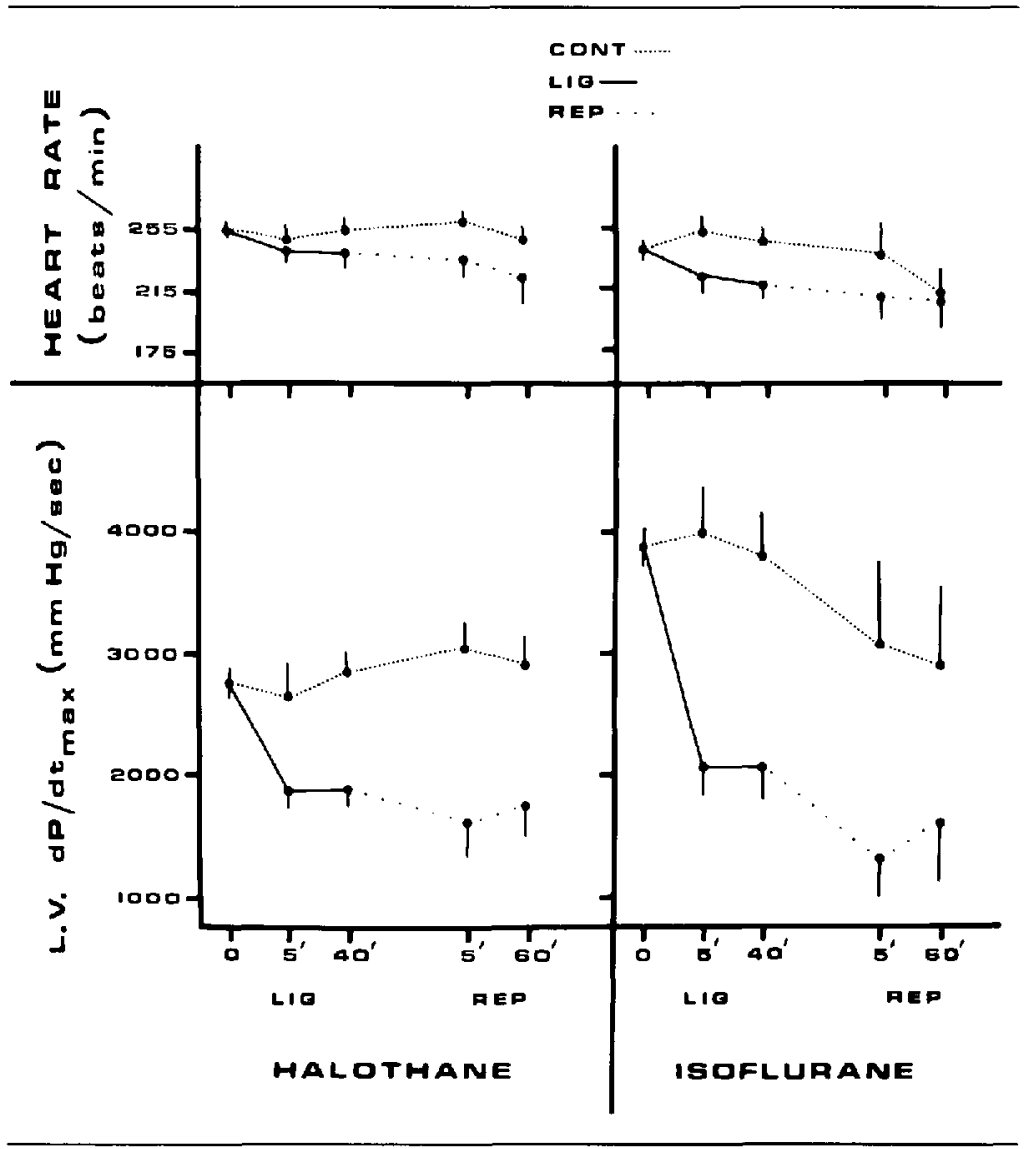

FIGURE 6 Heart rate and left ventricular contractility changes during ligation (lig) and reperfusion (rep) phases in halothane- and isoflurane-anaesthetized rabbits. (Experimental conditions as described in Figure 1.)

TABLE II Incidence of ventricular fibrillation and severe hypotension (systolic bp less than $25 \mathrm{mmHg}$ ) during ischacmia and reperfusion in rabbits anaesthetized with halothane or isoflurane

\begin{tabular}{lll}
\hline Drug & Ischaemic phase & Reperfusion phase \\
\hline $\begin{array}{ll}\text { Ventricular fibrillation } \\
\text { Halothane }\end{array}$ & $42 \%(11 / 26)$ & $38 \%(5 / 13)$ \\
Isoflurane & $70 \%(14 / 20)$ & $30 \%(3 / 10)$ \\
& & \\
Severe hypotension & & \\
$\quad$ Halothanc & $15 \%(4 / 26)$ & $31 \%(4 / 13)$ \\
Isoflurane & $25 \%(5 / 20)$ & $40 \%(4 / 10)$ \\
\hline
\end{tabular}

Data are expressed as percentage of the animals showing the abnormality in question. ischaemic/reperfusion conditions were small and did not differ between the two experimental groups (Figure 6)

The isoflurane group, when compared with the halothane-treated animals, showed a higher incidence of ischaemia-induced ventricular fibrillation, of severe hypotension (systolic pressure less than $25 \mathrm{mmHg}$, and requiring mechanical support) and of Q-wave appearance (Table II). Although these differences did not attain statistical significance, all are consistent with the indications from our chemical and biochemical studies that halothane affords greater protection to the myocardium from the effects of ischaemia than isoflurane. 


\section{Discussion}

The present study has compared the influence of two inhalational anaesthetics on the nature and extent of myocardial ischaemic/reperfusion injury following coronary artery ligation in the rabbit. Although the results found with the two inhalational agents were qualitatively similar and parallelled those we have previously reported using pentobarbitone anaesthesia in the same experimental model, ${ }^{3,6}$ a number of noteworthy differences were found. By several different criteria, halothane anaesthesia was associated with a lower degree of myocardial damage following $40 \mathrm{~min}$ of ischaemia and $60 \mathrm{~min}$ of reperfusion than was the case with isoflurane or pentobarbitone. When compared with halothane, isoflurane was associated with less recovery of both mitochondrial and sarcoplasmic reticular ATPase activities on reperfusion, greater alterations in myocardial tissue ions with reperfusion and a consistently higher incidence of cardiac electrical abnormalities and severe hypotension. However, both inhalational anaesthetics led to greater preservations of ATP levels, sarcolemmal ATPase activity and myocardial ionic composition than we have previously noted following coronary artery ligation and reperfusion in rabbits anaesthetized with pentobarbitone. ${ }^{6}$

The ability of halothane to diminish the adverse consequences of myocardial ischaemia has been demonstrated in a number of experimental systems. Halothane was found to decrease ST segment elevation following coronary artery ligation in $\operatorname{dogs}^{16,17}$ and this effect did not appear to be explainable in terms of haemodynamic alterations. ${ }^{17}$ Our results also suggest that the superior protection afforded by halothane as compared with isoflurane is probably not due primarily to differences in haemodynamic status during ischaemia. It has been shown that inhalation of one per cent halothane is able to increase the ratio of oxygen availability/oxygen consumption in a canine model of acute myocardial ischaemia. ${ }^{14}$ While this observation may be suggestive of possible alterations in regional blood flow, halothane, when tested under conditions associated with a significant reduction in infarct size in dogs subjected to $30 \mathrm{~min}$ of coronary artery ligation, did not detectably alter the endocardial/epicardial flow ratio in the region of ischaemia. ${ }^{18}$

The protective effects of halothane do not appear to necessarily involve a reduction in infarct size. Studies by MacLeod et al. in rats have shown that the administration of one per cent halothane beginning $30 \mathrm{~min}$ before and for $4 \mathrm{~h}$ following coronary artery ligation significantly decreased mortality and electrocardiographic abnormalities relative to conscious or fentanyl-treated animals, without producing any measureable change in occluded or infarcted zones. ${ }^{19}$ Indeed, there are reports that halothane under certain conditions may actually increase infarct size, ${ }^{20}$ possibly as the result of adverse haemodynamic effects. We have compared the actions of halothane and isoflurane at minimal anaesthetic concentrations which resulted in comparable blood pressure and $\mathrm{dP} / \mathrm{dt}_{\max }$ during ischaemic and reperfusion phases. Our results, therefore, suggest than an important consideration determining the superiority of halothane over a number of other anaesthetics, including pentobarbitone, meperidine and ketamine ${ }^{15,21}$ in different models of ischaemic injury, and over isoflurane in the present study may ultimately relate to an inherently greater capacity of halothane to preserve the integrity of sarcolemmal, mitochondrial and sarcoplasmic reticular membrane systems under conditions of ischaemia and subsequent reperfusion.

The disruption of cellular membranes is known to be a critical process determining the onset of irreversible ischaemic injury. Anaesthetics share in common the ability to interact with and perturb biological membranes as manifested, for example, in the stabilization of erythrocytes against hypotonic lysis at concentrations parallelling those producing anaesthesia. ${ }^{22}$ Experiments in our laboratory have shown that the red cell membrane perturbational characteristics of various anaesthetic agents, when tested at concentrations producing comparable degrees of antihaemolysis, are critically dependent on the chemical structure of the molecule in question. $8,9,23$ Studies of the in vitro effects of halothane, ether and chloroform on the behaviour of myocardial sarcolemmal, mitochondrial and myofibrillar ATPases have revealed a complex pattern of stimulatory and inhibitory actions which vary with the agent and the membrane involved. ${ }^{24,25}$

General anaesthetics are known to be capable of modifying the functional properties of mitochondria at anaesthetic concentrations, with electron transport being particularly susceptible. ${ }^{26,27}$ In our 
present study, cellular levels of ATP in control rabbits anaesthetized with halothane or isofurane were equivalent and comparable to those previously found in pentobarbitone-anaesthetized animals. ${ }^{6}$ Myocardial ATP content following $40 \mathrm{~min}$ of ischaemia decreased to approximately 30 per cent of control values with all three agents. In contrast to the further decrease in ATP levels (by approximately 15 per cent) upon reperfusion previously observed in pentobarbitone-anaesthetized animals, ${ }^{3}$ no further decline was detected with either halothane or isoflurane. This suggests a protective action of inhalational anaesthetics on some ATPconsuming process occurring during reperfusion. One likely possibility would involve ATP hydrolysis to energize the intracellular sequestration and/or extrusion of calcium, whose increased accumulation during reperfusion has been implicated in the mechanism of ischaemic/reperfusion injury. Myocardial calcium levels following $40 \mathrm{~min}$ of ischaemia and $60 \mathrm{~min}$ of reperfusion were approximately two-fold greater in rabbits anaesthetized with pentobarbitone $^{6}$ as compared with halothane or isoflurane anaesthesia. This difference also suggests that anaesthetic interactions at the level of the sarcolemmal membrane (thus resulting in decreased calcium influx) may be crucial in determining their influence on the course of ischaemic/reperfusion injury. Greater preservation of sarcolemmal integrity by the inhalational anaesthetics is also apparent in the lesser degree of inactivation of sarcolemmal $\mathrm{Na}^{+}, \mathrm{K}^{+}$-ATPase following ischaemia and reperfusion than we have previously found with pentobarbital. $^{6}$

It may well be, then, that sarcolemmal alterations induced by various pharmacological agents, including anaesthetics, are capable of modifying the course of myocardial ischaemic/reperfusion injury. However, the present findings indicate that the superior protective effects of halothane as observed here and in other experimental studies ${ }^{15-17,19,21}$ are not so readily accounted for on this basis. Halothane and isoflurane exerted comparable effects on two indices of sarcolemmal integrity, namely sarcolemmal $\mathrm{Na}^{+}, \mathrm{K}^{+}$-ATPase activity and myocardial calcium levels, although isoflurane-treated animals did show a significantly greater level of myocardial sodium, suggesting a lower degree of sarcolemmal stabilization. Halothane's greater preservation of mitochondrial and sarcoplasmic reticular ATPase activities during reperfusion indicates that effects of anaesthetics on subcellular organelles may also be crucial in determining their ability to modify the susceptibility of the myocardium to ischaemic/ reperfusion injury.

In summary, the results obtained here emphasize that the nature of the anaesthetic used in experimental investigations of myocardial ischaemia may influence, independently of alterations in cardiovascular status, the severity of cellular damage incurred. In particular, biochemical abnormalities are less marked with the two inhalational agents examined than with pentobarbitone, which is commonly employed in animal models of acute myocardial infarction. It is not fully known to what extent the superior protective actions of halothane observed here and in studies by others would be of clinical advantage in patients at risk of developing perioperative myocardial ischaemic injury, although this would seem to warrant more detailed investigation. However, considerable caution must be exercised in extrapolating the results of experiments on acute myocardial infarction in anaesthetized animals, particularly when pentobarbitone is used, to the clinical situation in man.

\section{Acknowledgements}

We are grateful for the expert technical assistance provided by Mrs. Therese $\mathrm{Ng}$ and Ms. Maureen Garnett and also express our gratitude to Drs. L. C. Jenkins and B. A. Saunders for their encouragement and support.

\section{References}

1 Carmeliet E. Myocardial ischemia: reversible and irreversible changes. Cire 1984; 70: 149-51.

2 Hearse DJ. Reperfusion of the ischemic myocardium. J Molec Cell Cardiol 1977; 9: 605-16.

3 Godin DV. Tuchek JM, Moore MM. Membrane alterations in acute myocardial ischemia. Can J Biochem 1980; 58: 777-86.

4 Chien KR, Pfau RG, Farber JL. Ischemic myocardial cell injury. Prevention by chlorpromazine of an accelerated phospholipid degradation and associated membrane dysfunction. Am J Pathol 1979; 97 : 505-30.

5 Vogel WNM, Romson $J$, Bush LR, Shlafer $M$, Lucchesi $B R$. Protective effects of dimethylpropranolol (UB-272) during global ischemia of iso- 
lated feline hearts. J Pharmacol Exp Ther 1980; 212: 560-8.

6 Moore $M M$, Godin $D V$. The protective effects of D-600 and propranolol on reperfusion injury in the anaesthetized rabbit. Can J Physiol Pharmacol 1984; 62: 212-23.

7 Lenaz G, Curatola G, Mazzanti L, ParentiCastelli $G$. Biophysical studies on agents affecting the state of membrane lipids: biochemical, and pharmacological implications. Molec Cell Biochem 1978; 22: 3-33.

8 Godin DV, Del Vicario G. Molecular aspects of inhalational anaesthetic interaction with excitable and non-excitable membranes. Can Anaesth Soc J 1981; 28: 201-9.

9 Godin DV, McGinn P. Perturbational actions of barbiturate analogues on erythrocyte and synaptosomal membranes. Can J Physiol Pharmacol 1985; 63: 937-43.

10 Hoffmeister FS, Regelson W, Rubin $H$. Effect of central depression on survival following acute coronary occlusion. Surg Forum 1958; 9: 242-5.

11 Majewska MD, Strosznajder J, Lazarewicz J. Effect of ischemic anoxia and barbiturate anesthesia on free radical oxidation of mitochondrial phospholipids. Brain Res 1978; 158: 423-34.

12 Smith MW, Collan $Y$, Wonkahng $M$, Trump BF. Changes in mitochondrial lipids of rat kidney during ischemia. Biochem Biophys Acta 1980; 618: 192201.

13 Komai H, Berkof HA, Rusy BF. Protection of ischemic rat heart by cardioplegic doses of pentobarbital. J Surg Res 1981; 30: 42-6.

14 Smith $G$, Rogers $K$, Thorburn J. Halothane improves the balance of oxygen supply to demand in acute experimental myocardial ischacmia. $\mathrm{Br} J$ Anaesth 1980; 52: 577-83.

15 AuTLS, Collins GA, Macleod BA, Walker MJA. Effects of prostaglandin $E_{2}$, propranolol and nitroglycerine with halothane, pethidine or pentobarbitone anaesthesia on arrhythmias and other responses to ligation of a coronary artery in rats. $\mathrm{Br} J$ Pharmac 1983; 79: 929-37.

16 Bland $J H L$, Lowenstein E. Halothane-induced decrease in experimental myocardial ischemia in the non-failing canine heart. Anesthesiology 1976; 45: 287-93.

17 Gerson Jl, Hickey RF, Bainton CR. Treatment of myocardial ischemia with halothane or nitroprussidepropranolol. Anesth Analg 1982; 61: 10-4.
18 Davis RF, De Boer LWV, Rude RE, Lowenstein E, $M a r o k o P R$. The effect of halothane anaesthesia on myocardial necrosis, hemodynamic performance and regional myocardial blood flow in dogs following coronary artery occlusion. Anesthesiology 1983; 59: 402-11.

19 Macleod BA, Augereau P, Walker MJA. Effects of halothane anesthesia compared with fentanyl anesthesia and no anesthesia during coronary ligation in rats. Anesthesiology 1983; 58: 44-52.

20 Kissen I, Stanbridge R, Bishop SP, Reeves JG. Effect of halothane on myocardial infarct size in rats. Can Anesth Soc J 1981; 28: 239-43.

21 Barrister PH, Longnecker DE. Influence of anaesthetic agents on the survival of rats following acute ischaemia of the bowel. Br J Anaesth 1979; 51 : 921-5.

22 Seeman $P$. Membrane actions of anesthetics and tranquilizers. Pharmacol Rev 1972; 24: 583-655.

23 Godin DV, AuT, Garnetr ME. Membrane perturbational effects of antiarrhythmic drugs. J Molec Cell Cardiol 1979; 11: 261-74.

24 Lee SL, Alto LE, Dhalla NS. Effects of some volatile anesthetic agents on rat heart sarcolemma. Life Sci 1979; 24: 1441-6.

25 Lee SL, Alto LE, Dhalla NS. Subcellular effects of some anesthetic agents on rat myocardium. Can J Physiol Pharmacol 1979; 57: 65-70.

26 Altura BM. Cardiovascular actions of general anaesthetics. Fed Proc 1980; 39: 1574.

27 Kissen 1, Aultman DF, Smith $L R$. Effects of volatile anesthetics on myocardial oxidation-reduction status assessed by NADH fluorometry. Anesthesiology 1983; 59: 447-52. 
Résumé

Les effets de l'anesthésie à l' halothane et l' isoflurane sur les lésions myocardiques chez les lapins ayant subi une ligature d'une artère coronaire et subséquemment reperfusé ont été analysés. Même si l'halothane et l' isoflurane (des concentrations inspirées de 1.0 et 1.5 pour cent respectivement) ont présenté des effets cardiovasculaires comparables durant l'ischémie et la reperfusion, on observa une plus grande préservation de l'intégrité des structures cellulaires (évalué par des altérations des mitochondries et de l'activité de la ATPase du reticulum sarcoplasmique ainsi que des alterations ioniques du myocarde) avec l'halothane. On observa aussi une incidence plus basse de fibrillation ventriculaire et d'hypotension sévère avec l'halothane. Nos résultats indiquent que lors d'études expérimentales sur l' ischémie myocardique, les agents anesthésiques peuvent indépendamment de leurs actions cardiovasculaires influencer la nature et l'étendue des lésions crées possiblement en veriue de leurs effets différents sur le système des membranes intra-cellulaires. 